\title{
BIFIDOBACTERIUM BIFIDUM BB28 MICROENCAPSULATED WITH CA-ALGINATE: SURVIVAL UNDER SIMULATED GASTROINTESTINAL CONDITIONS AND STABILITY DURING STORAGE
}

\author{
G.W. SHU ${ }^{\mathrm{a}}$, D.L. MA ${ }^{\mathrm{a} *}$, H. CHEN ${ }^{\mathrm{a}}$, J.P. MenG ${ }^{\mathrm{b}}$, Y. WANG ${ }^{\mathrm{a}}$ and N. XIN \\ aSchool of Food and Biological Engineering, Shaanxi University of Science and Technology, Xi’an, 710021. China \\ 'Xi'an Baiyue Goat Milk Corp., Ltd., Xi’an, 710089. China
}

(Received: 27 February 2017; accepted: 26 May 2017)

\begin{abstract}
The present study was to evaluate the survival rate of free and encapsulated Bifidobacterium bifidum BB28 under simulated gastrointestinal conditions and its stability during storage. Results showed that non-microencapsulated Bifidobacterium bifidum BB28 was more susceptible to simulated gastrointestinal conditions than microencapsulated bacteria. Microencapsulated Bifidobacterium BB28 exhibited a lower population reduction than free cells during exposure to simulated gastrointestinal conditions, the viable count of monolayer microcapsules, double layer microcapsules, and triple layer microcapsules decreased by nine magnitudes, four magnitudes, and one magnitude after 2 h, respectively. The enteric test showed that the microorganism cells were released from the monolayer, double layer, and triple layer microcapsules completely in $40 \mathrm{~min}$. Moreover, the optimum storage times of free Bifidobacterium BB28, monolayer microcapsules, double layer microcapsules, and triple layer microcapsules were 21 days, 21 days, 28 days, and more than 35 days in orange juice, pure milk, and nutrition Express (a commercially available milk based drink), and the viable counts were maintained at $1 \times 10^{6} \mathrm{CFU} \mathrm{g}^{-1}$ or more, which means that the double layer and triple layer of microcapsules of B. bifidum BB28 have great potential in food application.
\end{abstract}

Keywords: Bifidobacterium bifidum BB28, stability, survival, microencapsulation, simulated gastrointestinal

Probiotics are living microorganisms, which are beneficial to human health (FAO/WHO, 2002). Lactobacilli and bifidobacteria species have shown beneficial effects on immunomodulation and on susceptibility to various intestinal diseases (КнАн. 2007; DENKOVA et al., 2011). However, these probiotics are also fastidious and obligate anaerobes, which pose a technological challenge for the dairy industry. To utilize their beneficial properties, probiotics must be able to tolerate the acidic conditions in the stomach environment as well as bile in the small intestine (Doleyres et al., 2004). The acidic environment in the stomach and bile salts secreted into the duodenum are the main obstacles to the survival of the ingested bacteria. In general, bifidobacteria have a relatively lower tolerance for the $\mathrm{pH}$ of the gastric juice (Collado \& SANZ, 2006). Moreover, the survival rate of probiotics during processing and storage of food is also essential for the development of products that have an adequate number of viable cells (ANAL \& SingH, 2007). The benefits promoted by probiotic bacteria are increasingly explored in different uses in various types of foods (SouzA \& SAAD, 2009). Nowadays, the application of non-milk-based probiotic preparations used to obtain beverages or directly as probiotic tablets, capsules, or lyophilized preparations increases (DeNKova et al., 2014).

\footnotetext{
* To whom correspondence should be addressed. Phone: +18710750260; e-mail: 994681086@qq.com
} 
Microencapsulation is a promising technique to render physical protection and improve the stability of probiotic organisms in functional food products (Gouin, 2004; ANAL \& SingH, 2007; BRINQUes \& MAz, 2011). However, results showed that the survival rate of probiotics after exposure to acid are rarely satisfactory, and when a high protection against gastric juice was noted, the survival of the cells dramatically decreased within a few weeks during storage (Albertini et al., 2010).

The aim of this paper is to evaluate the survival rate of Ca-alginate microencapsulated Bifidobacterium bifidum BB28 (B. bifidum BB28) in artificially simulated gastric juices, bile salt, and intestinal tract, and to study the stability of microencapsulation of B. bifidum BB28 in food.

\section{Materials and methods}

\subsection{Materials}

The strain of B. bifidum BB28 was obtained from School of Food \& Biology Engineering, Shaanxi University of Science \& Technology. Alginate (Luo Senbo Technology Co., Ltd. Xi'an), was used as carrier agent and MRS broth (Hope Bio-Technology Co., Ltd. Qingdao) as cultivation medium. All chemicals used were of analytical grade. Centrifuge (LG10-2.4) was used to obtain microcapsules.

\subsection{Microorganism}

B. bifidum BB28 was cultured for $24 \mathrm{~h}$ in MRS medium at $37^{\circ} \mathrm{C}$, the cells were harvested by centrifugation at $1500 \times \mathrm{g}$ for $10 \mathrm{~min}$ at $4{ }^{\circ} \mathrm{C}$, and washed twice before suspending them in 5 $\mathrm{ml}$ normal saline. The final cell concentration was adjusted to $1.0 \times 10^{11} \mathrm{CFU} \mathrm{ml}{ }^{-1}$.

\subsection{Microencapsulation}

B. bifidum BB28 was encapsulated in sodium alginate matrix. Sodium alginate solutions (2\% $\mathrm{w} / \mathrm{v})$ and chitosan solution ( $1 \% \mathrm{w} / \mathrm{v}, \mathrm{pH} 5.3)$ were prepared, sterilized by autoclaving $\left(120^{\circ} \mathrm{C}\right.$ for $15 \mathrm{~min}$ ) and cooled to $38-40^{\circ} \mathrm{C}$. Palm oil (food grade) was prepared, melted for $15 \mathrm{~min}$ at $37{ }^{\circ} \mathrm{C}$. $2 \%$ sodium alginate solutions $(10 \mathrm{ml})$ and $1 \mathrm{ml}$ of free cell suspension were transferred into a centrifuge tube, and the content was vortexed to homogeneity. The alginatecell mixture was added dropwise to a beaker (300 ml) containing an emulsion of oil and water in ratio 5:1, containing $0.4 \%$ Tween 80 , while stirring magnetically. After $15 \mathrm{~min}$, a uniformly turbid emulsion was obtained where $2 \%$ calcium chloride was quickly added to harden microcapsules and break the emulsion. The monolayer microcapsules (MM) were harvested by centrifugation at $1500 \times \mathrm{g}$ for $10 \mathrm{~min}$. To form chitosan coated sodium alginate double layer microcapsules (DM), 1\% chitosan solution was added and mixed with the above-mentioned monolayer microcapsules for $30 \mathrm{~min}$, and washed with sterile saline solution for three times. Finally, the palm oil coated sodium alginate-chitosan beads were formed by adding palm oil, mixing for $30 \mathrm{~min}$, and washing with sterile saline solution for three times. Thus, free B. bifidum BB28, alginate sodium encapsulated B. bifidum BB28 cells (MM), alginate-chitosan encapsulate B. bifidum BB28 (DM), and alginate-chitosan-palm oil encapsulate B. bifidum BB28 (TM) were obtained for further evaluation of survival and storage stability. 


\subsection{Viable count}

The $1 \mathrm{~g}$ capsules were transferred into test tubes containing $9 \mathrm{ml}$ tri-sodium citrate to free the encapsulated bacteria. The samples were diluted tenfold by sterile saline solution, and the appropriate dilutions were transferred to anaerobic tubes containing MRS agar, then incubated at $37^{\circ} \mathrm{C}$ for $48 \mathrm{~h}$. The method for counting viable bacteria was described by CHEN and coworkers (2012).

\subsection{Survival of microencapsulated and non-microencapsulated B. bifidum BB28 under simulated gastrointestinal conditions}

1.5.1. Gastric juice tolerance test. The simulation of gastric juice conditions was done in $\mathrm{HP}$ medium $(0.16 \%$ hydrogen chloride, $0.1 \%$ pepsin) with $\mathrm{pH}$ adjusted to 1.2 . One gram of microcapsules or $1.0 \mathrm{ml}$ of free suspended cells was added to test tubes containing $9 \mathrm{ml}$ of HP medium. The tubes were incubated at $37{ }^{\circ} \mathrm{C}$ and samples were collected in triplicate at $0 \mathrm{~h}$, $1 \mathrm{~h}$, and $2 \mathrm{~h}$. The viable counts of the free and encapsulated B. bifidum BB28 were evaluated as described in Section 1.4.

1.5.2. Bile salt tolerance test. To determine the resistance to bile salts, $1 \mathrm{ml}$ of free and $1 \mathrm{~g}$ of encapsulated cells were transferred to $9 \mathrm{ml}$ solution containing $1 \%$ bile salts. Triplicate samples were collected after incubation at $37^{\circ} \mathrm{C}$ for $0 \mathrm{~h}, 1 \mathrm{~h}$, and $2 \mathrm{~h}$. Cell counts of the free and encapsulated bacteria were enumerated as described in Section 1.4.

1.5.3. Simulated intestinal fluid test. To evaluate the release time of microencapsulated cells in simulated intestinal fluid, microcapsules $(1 \mathrm{~g})$ were added to test tubes containing $9 \mathrm{ml}$ pre-warmed $37^{\circ} \mathrm{C}$ simulated intestinal fluid (1.38\% potassium dihydrogen phosphate, $0.4 \%$ sodium hydroxide, and $1 \%$ pancreatic enzymes), and samples in triplicate were taken after incubation at $37^{\circ} \mathrm{C}$ for $0 \mathrm{~h}, 1 \mathrm{~h}$, and $2 \mathrm{~h}$. The viable counts were enumerated as described in Section 1.4.

\subsection{Evaluation of the stability of microencapsulated B. bifidum BB28 in juice, nutrition Express, and pure milk}

One g of microcapsulated B. bifidum BB28 was added to $9 \mathrm{ml}$ of orange juice, nutrition Express, and pure milk, and then the viable count, $\mathrm{pH}$, and acidity were measured every 7 days while storage at $4{ }^{\circ} \mathrm{C}$ and room temperature. Also, the control group experiments were performed by adding $B$. bifidum BB28 free cell suspension to orange juice, nutrition Express, and pure milk.

\subsection{Determination of $p H$}

The acidity meter PHs-3c was used to determine the $\mathrm{pH}$ at room temperature (HE et al., 2011; SHu et al., 2012).

\subsection{Determination of acidity}

The determination of acidity was performed according to DenKova and co-workers (2012). 


\section{Results and discussion}

\subsection{Survival of B. bifidum BB28 in simulated gastrointestinal conditions}

2.1.1. Gastric juice tolerance test. As seen from Table 1, there was a significant decrease in the viability of free B. bifidum BB28 cells and monolayer microcapsules compared to double layer and triple layer microcapsules under simulated acidic conditions. The viable counts of free B. bifidum BB28 and monolayer microcapsules in $2 \mathrm{~h}$ decreased to 0. For the other two samples the protection provided by the chitosan was due to strong bonding between chitosan and alginate by electrostatic interactions, leading to formation of a membrane on the surface of the granules. Similar results were obtained by ANNAN and co-workers (2008), which illustrated double and triple layer Bifidobacterium microcapsules had a better stability and stronger resistance to acid. On the other hand, Sun and GrifFITHs (2000) found that the viable count of free Bifidobacterium decreased from $1.233 \times 10^{9} \mathrm{CFU} \mathrm{ml}{ }^{-1}$ to an undetectable level in $30 \mathrm{~min}$, however, the viable count of immobilized cells in gellan-xanthan beads decreased by only 0.67 log cycle in the same time interval, and $6.3 \times 10^{5} \mathrm{CFU} \mathrm{ml}{ }^{-1}$ remained after $120 \mathrm{~min}$, which suggested that immobilization protected further Bifidobacterium from the extreme acid environment in the human stomach. The microencapsulation efficiency for monolayer, double layer, and triple layer microcapsules were $88.24 \%$, 89.24\%, and $100 \%$ in present experiment, respectively.

Table 1. Viability of microencapsulated and non-microencapsulated B. bifidum BB28 under simulated acidic conditions ( $\mathrm{CFU} \mathrm{g}{ }^{-1}$ )

\begin{tabular}{lccc}
\hline Samples & 0 & $1 \mathrm{~h}$ & $2 \mathrm{~h}$ \\
\hline FS & $4.41 \times 10^{9}$ & $1.09 \times 10^{3}$ & 0 \\
MM & $2.14 \times 10^{9}$ & $6.23 \times 10^{4}$ & 0 \\
DM & $1.97 \times 10^{9}$ & $3.92 \times 10^{7}$ & $5.79 \times 10^{5}$ \\
TM & $1.97 \times 10^{9}$ & $1.02 \times 10^{9}$ & $5.36 \times 10^{8}$ \\
\hline
\end{tabular}

FS: free cell suspension; MM: monolayer microcapsules; DM: double layer microcapsules; TM: triple layer microcapsules

2.1.2. Bile salt tolerance test. Table 2 shows that the viable count of free $B$. bifidum BB28 and monolayer microcapsules decreased to 0 after $2 \mathrm{~h}$, but the viable count of double layer and triple layer microcapsules were $6.89 \times 10^{5} \mathrm{CFU} \mathrm{ml} \mathrm{m}^{-1}$ and $5.92 \times 10^{8} \mathrm{CFU} \mathrm{ml} \mathrm{m}^{-1}$, respectively. The mall materials used for microencapsulation were chitosan and palm oil, which improved the viability of B. bifidum BB28. Similar results were obtained by CHÁvARRI and co-workers (2010).

Prebiotics can promote the growth of probiotics in microcapsules. Previous research indicated that chitosan coating could protect microcapsules in bile salt solution due to an ion exchange reaction (SHI et al., 2013a; b). In addition, SoHAIL and co-workers (2011) found that the survival rate of probiotics was highly dependent on the species microencapsulated. Castro-Cislaghi and co-workers (2012) found that microencapsulation with whey failed to protect probiotic cells, but in the current study, when using sodium alginate, chitosan, and palm oil to protect probiotic cells, the results showed that the survival rate of encapsulated $B$. bifidum BB28 was satisfactory in bile. 
Table 2. Viability of microencapsulated and non-microencapsulated B. bifidum BB28 under simulated bile conditions (CFU g-1)

\begin{tabular}{lccc}
\hline Samples & 0 & $1 \mathrm{~h}$ & $2 \mathrm{~h}$ \\
\hline FS & $4.41 \times 10^{9}$ & $2.01 \times 10^{3}$ & 0 \\
MM & $2.14 \times 10^{9}$ & $0.93 \times 10^{5}$ & 0 \\
DM & $1.97 \times 10^{9}$ & $3.78 \times 10^{7}$ & $6.89 \times 10^{5}$ \\
TM & $1.97 \times 10^{9}$ & $1.12 \times 10^{9}$ & $5.92 \times 10^{8}$ \\
\hline
\end{tabular}

FS: free cell suspension; MM: monolayer microcapsules; DM: double layer microcapsules; TM: triple layer microcapsules

2.1.3. In vitro enteric test. Table 3 shows the viability of microencapsulated B. bifidum BB28 released under simulated enteric tract conditions. It can be seen that the viable count reached the maximum when the microcapsules were treated for $40 \mathrm{~min}$, however, the number of living bacteria showed a downward trend after that. The enteric test showed the microorganism cells were released from the monolayer, double layer, and triple layer microcapsules completely in $40 \mathrm{~min}$, so the method by microencapsulating to protect probiotics was effective. Moreover, MARTONI and co-workers (2007) verified an increase in viability of $0.9-1.0 \log \mathrm{CFU} \mathrm{ml} \mathrm{m}^{-1}$ when $L$. plantarum $80 \mathrm{BSH}+$ strain was exposed to simulated intestinal conditions for a $10 \mathrm{~h}$ incubation time.

Table 3. Viability of microencapsulated B. bifidum BB28 released under simulated enteric tract conditions $\left.(\mathrm{CFU} \mathrm{g})^{-1}\right)$

\begin{tabular}{lccc}
\hline Samples & $20 \mathrm{~min}$ & $40 \mathrm{~min}$ & $60 \mathrm{~min}$ \\
\hline $\mathrm{MM}$ & $1.90 \times 10^{7}$ & $2.14 \times 10^{9}$ & $1.90 \times 10^{9}$ \\
$\mathrm{DM}$ & $3.83 \times 10^{6}$ & $1.97 \times 10^{9}$ & $1.09 \times 10^{9}$ \\
$\mathrm{TM}$ & $1.12 \times 10^{6}$ & $1.97 \times 10^{9}$ & $1.81 \times 10^{9}$ \\
\hline
\end{tabular}

MM: monolayer microcapsules; DM: double layer microcapsules; TM: triple layer microcapsules

2.2. The stability for the microcapsules of $\mathrm{B}$. bifidum $B B 28$ in orange juice, nutrition Express, and pure milk. Figures 1 to 2 show the stability of free B. bifidum BB28, monolayer microcapsules, double layer microcapsules, and triple layer microcapsules in orange juice and nutrition Express. It can be seen from the figures that the viable counts of B. bifidum BB28 under $4{ }^{\circ} \mathrm{C}$ and room temperature decreased in the following order: free cells, monolayer microcapsules, double layer microcapsules, and triple layer microcapsules. The main reason for the decrease in the number of viable bacteria was the acidic environment in orange juice and nutrition Express, which could inhibit or even kill some of the bacteria, but the viable count was maintained at $1 \times 10^{6} \mathrm{CFU} \mathrm{g}^{-1}$ or more, for double layer and triple layer microcapsules after 28 days. Figure 3 shows that the viable counts of free B. bifidum BB28, monolayer microcapsules, double layer microcapsules, and triple layer microcapsules remained $10^{10} \mathrm{CFU} \mathrm{g}{ }^{-1}$ in pure milk at $4{ }^{\circ} \mathrm{C}$, but the viable count increased to $10^{12} \mathrm{CFU} \mathrm{g}^{-1}$ at room temperature, the reason for this phenomenon were that the temperature promoted the growth and reproduction of the bacteria, what's more, the $\mathrm{pH}$ value of pure milk was close to neutral, 

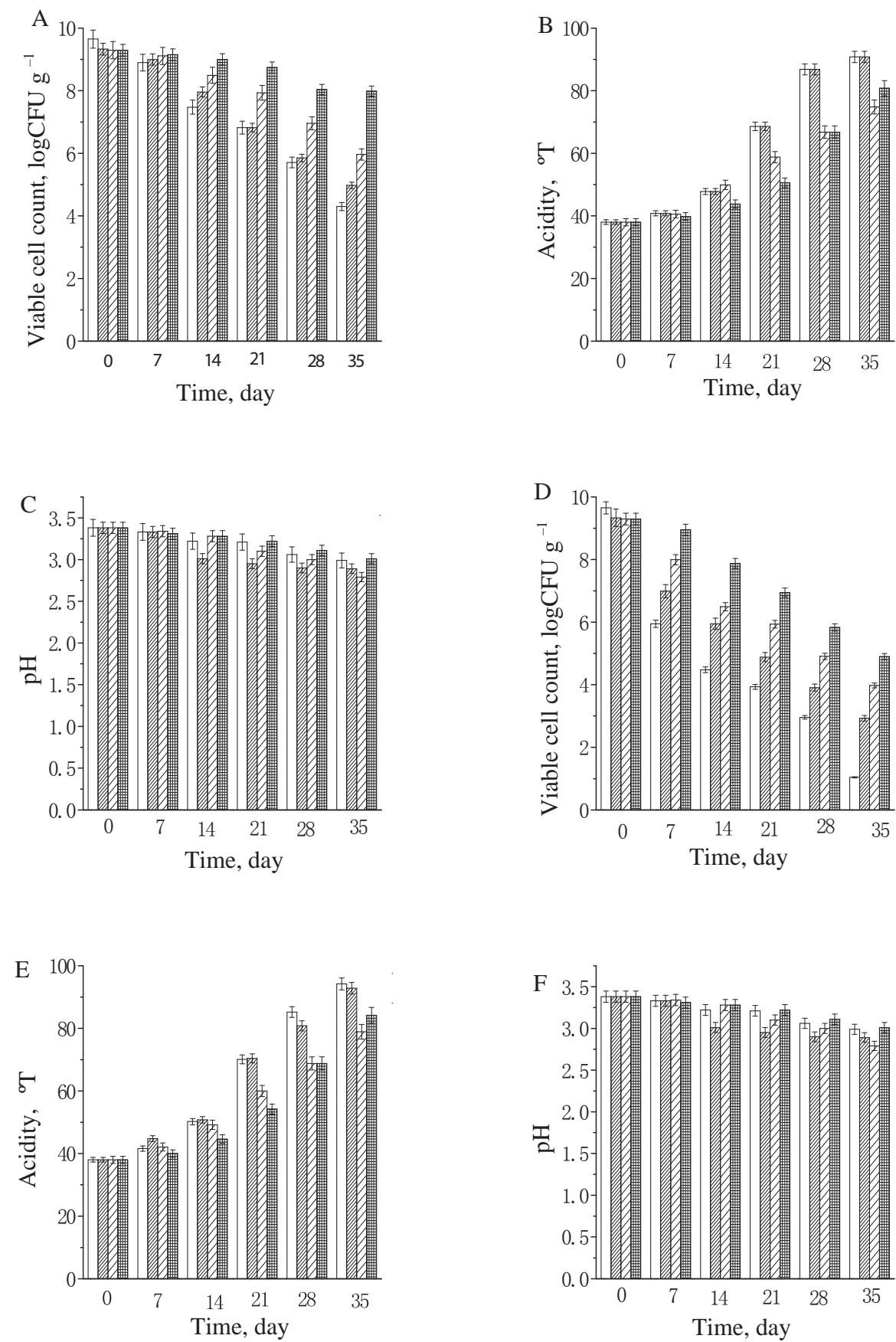

Fig. 1. The viable cell count, acidity, and $\mathrm{pH}$ of $\mathrm{B}$. bifidum $\mathrm{BB} 28$ in fruit orange stored at $4{ }^{\circ} \mathrm{C}(\mathrm{A}, \mathrm{B}, \mathrm{C})$ and room temperature (D, E, F) (FS: free cell suspension; MM: monolayer microcapsules; DM: double layer microcapsules; TM: triple layer microcapsules)

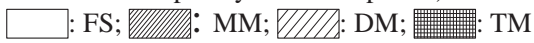



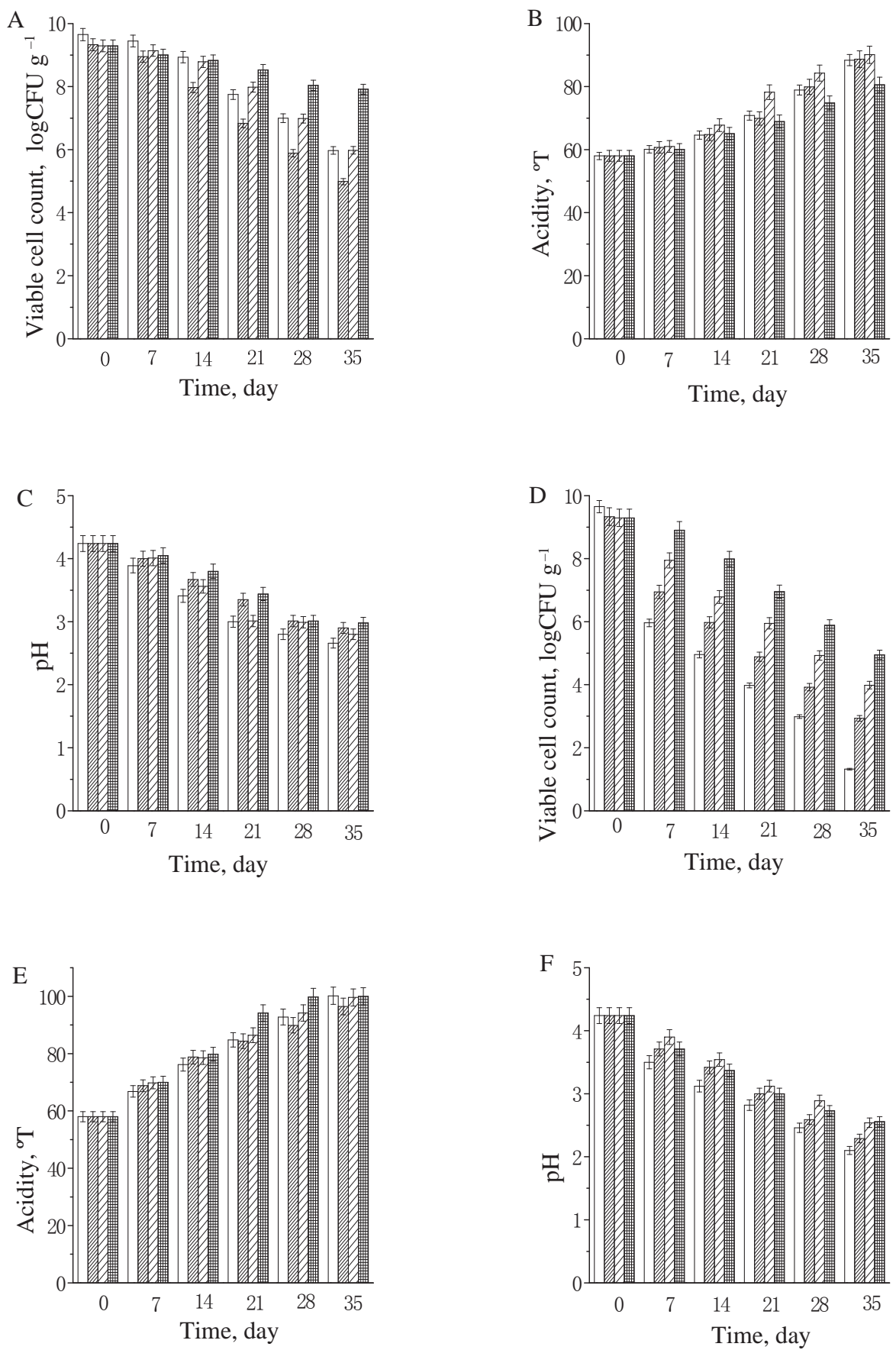

Fig. 2. The viable cell count, acidity, and $\mathrm{pH}$ of $\mathrm{B}$. bifidum BB28 in nutrition Express stored at $4{ }^{\circ} \mathrm{C}$ (A, B, C) and room temperature (D, E, F) (FS: free cell suspension; MM: monolayer microcapsules; DM: double layer microcapsules; TM: triple layer microcapsules)

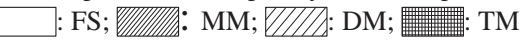


A
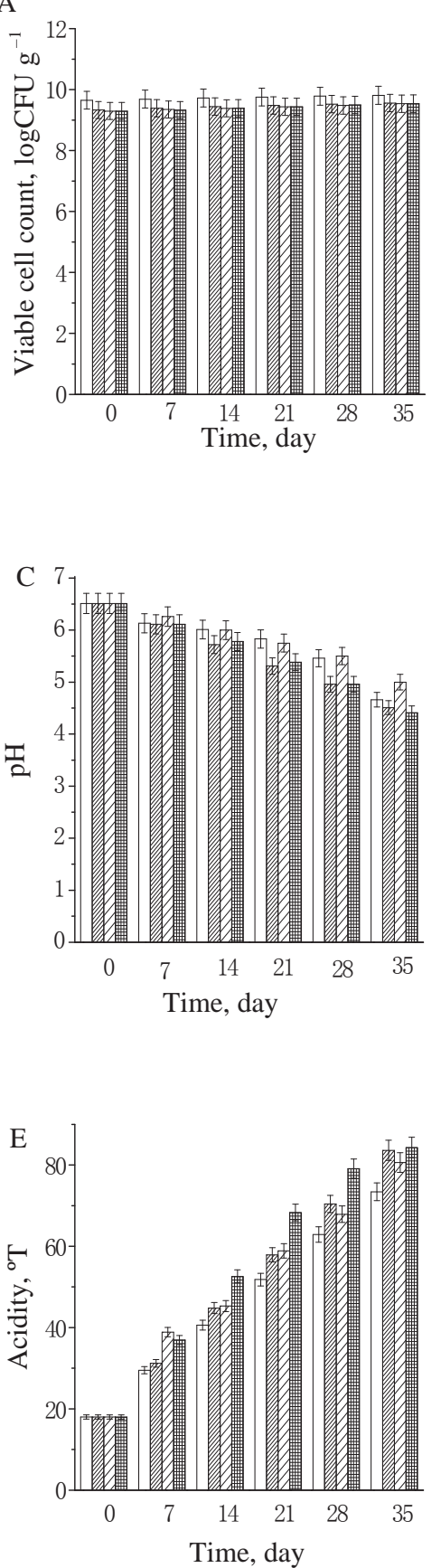
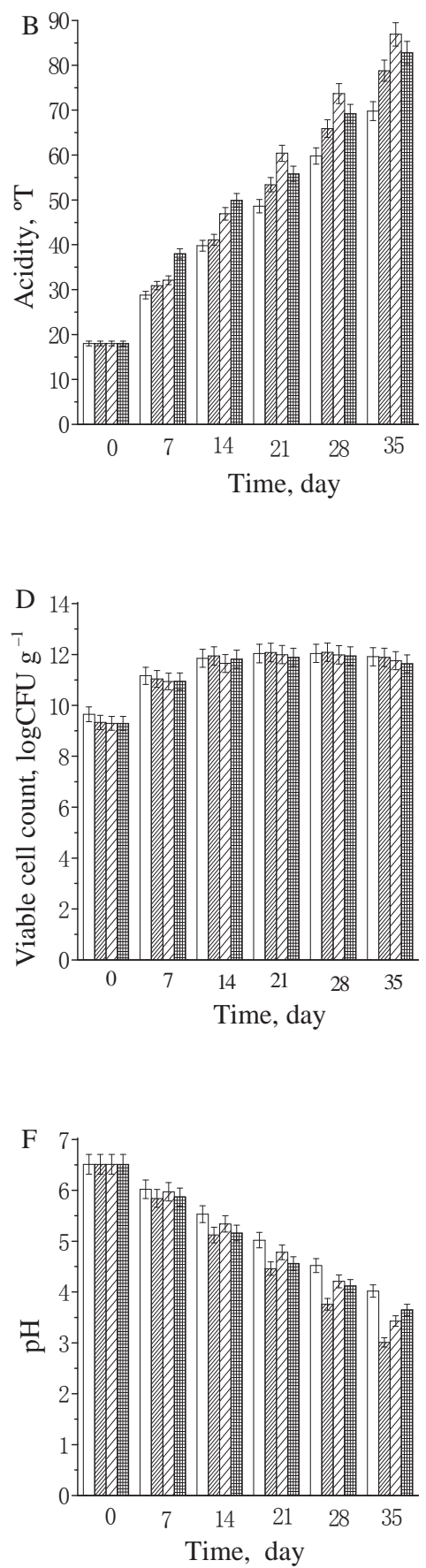

Fig. 3. The viable cell count, acidity, and pH of B. bifidum BB28 in pure milk stored at $4{ }^{\circ} \mathrm{C}$ (A, B, C) and room temperature (D, E, F) (FS: free cell suspension; MM: monolayer microcapsules; DM: double layer microcapsules; TM: triple layer microcapsules)

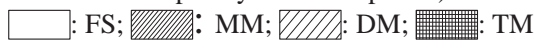


which was suitable for the preservation of B. bifidum BB28. It can be concluded from the figures that the optimum storage times of free B. bifidum BB28, monolayer microcapsules, double microcapsules, and triple layer microcapsules were 21 days, 21 days, 28 days, more than 35 days; and 7 days, 14 days, 21 days and 28 days at $4{ }^{\circ} \mathrm{C}$ and room temperature, respectively. Nevertheless, Gross and FÁVARO-TRINDADE (2004) found the number of viable cells of immobilized $B$. lactis in yoghurt presented a gradual decline during the whole storage period, passing from $10^{8} \mathrm{CFU} \mathrm{ml}{ }^{-1}$ to no count after 28 days of storage, the reasons for this phenomenon were inhibitory substances produced by the yoghurt culture or an excess of dissolved oxygen. But MATIAS and co-workers (2016) found the populations of Bifidobacterium $\mathrm{Bb}-12$ were slightly exceeding $6 \log \mathrm{CFU} \mathrm{g}{ }^{-1}$ in ice cream with oligofructose at 90 days of storage; meanwhile the viability of $B$. animalis $\mathrm{Bb}-12$ in all synbiotic apple ice cream formulations tested was satisfactory until the 84th day of frozen storage, with populations of around 7.5 to $8.5 \log \mathrm{CFU} \mathrm{g}^{-1}$.

\section{Conclusions}

In this study, acid and bile salt resistance results showed that the viable count of free $B$. bifidum BB28 decreased to 0 after 2 hours in simulated bile salt and gastric juice, and the viable counts of monolayer, double layer, and triple layer microcapsules decreased by nine magnitudes, four magnitudes and one magnitude, respectively. The enteric test showed that the microorganism cells were released completely from the microcapsules under simulated intestinal fluid in $40 \mathrm{~min}$, which demonstrated the applicability of microcapsules of B. bifidum BB28 in food. In addition, the optimum storage times, maintaining $1 \times 10^{6} \mathrm{CFU} \mathrm{g}^{-1}$ or more, of free B. bifidum BB28, monolayer microcapsules, double layer microcapsules, and triple layer microcapsules were 21 days, 21 days, 28 days, and more than 35 days, respectively, at $4{ }^{\circ} \mathrm{C}$; and 7 days, 14 days, 21 days, and more than 28 days, respectively, at room temperature overall in orange juice, pure milk, and nutrition Express. The experimental results showed that the double layer and the triple layer microcapsules of B. bifidum BB28 had great application possibilities in food.

The authors wish to gratefully acknowledge Doctoral Scientific Research Fund from Shaanxi University of Science \& Technology (No. 2017BJ-04) and the Science and Technology Overall Planning for Innovation Engineering project of Shaanxi Province (No. 2016KTZDNY02-08).

\section{References}

Albertini, B., Vitali, B., Passerini, N., Cruciani, F., Sabatino, M.D., Rodriguez, L. \& Brigidi, P. (2010): Development of microparticulate systems for intestinal delivery of Lactobacillus acidophilus and Bifidobacterium lactis. Eur. J. Pharm. Sci., 40, 359-366.

AnAL, A.K. \& SingH, H. (2007): Recent advances in microencapsulation of probiotics for industrial applications and targeted delivery. Trends Food Sci. Tech., 18(5), 240-251.

Annan, N.T., Borza, A.D. \& Hansen, L.T. (2008): Encapsulation in alginate-coated gelatin microspheres improves survival of the probiotic Bifidobacterium adolescentis 15703t during exposure to simulated gastrointestinal conditions. Food Res. Int., 41(2), 184-193.

Brinques, G.B. \& MAZ, A. (2011): Effect of microencapsulation on survival of Lactobacillus plantarum in simulated gastrointestinal conditions, refrigeration, and yogurt. J. Food Eng., 103(2), 123-128. 
Castro-Cislaghi, F.P.D., Silva, C.D.R.E., Fritzen-Freire, C.B., Lorenz, J.G. \& Sant’Anna, E.S. (2012): Bifidobacterium BB-12 microencapsulated by spray drying with whey: Survival under simulated gastrointestinal conditions, tolerance to $\mathrm{NaCl}$, and viability during storage. J. Food Eng., 113(2), 186-193.

Chávarri, M., Marañón, I., Ares, R., Ibáñez, F.C., Marzo, F. \& Villarán, M.C. (2010): Microencapsulation of a probiotic and prebiotic in alginate-chitosan capsules improves survival in simulated gastrointestinal conditions. Int. J. Food Microbiol., 142(1-2), 185-189.

Chen, H., WAnG, Y., Shu, G.W. \& Jia, Y.L. (2012): Effect of alginate and cell suspension on viable count and efficacy of entrapment of encapsulated B. bifidum BB28. Adv. Mater. Res., 531, 499-502.

Collado, M.C. \& SAnZ, Y. (2006): Method for direct selection of potentially probiotic Bifidobacterium strains from human feces based on their acid-adaptation ability. J. Microbiol. Meth., 66(3), 560-563.

Denkova, R., Ilieva, S., Denkova, Z., Georgieva, L., Yordanova, M., Nikolova, D. \& Yana, E. (2011): Production of wheat bread without preservatives using sourdough starters. Biotechnol. Biotec. Eq., 28, 889-898.

Denkova, Z., Dobrev, I., Denkova, R., Yanakieva, V. \& Kozludzhova, S. (2014): Pea probiotic foods and beverages during storage. Journal of Food and Packaging Science, Technique and Technologies, 3, 69-73.

Denkova, R., Yanakieva, V., Denkova, Z., Urshev, Z., Goranov, B. \& Sotirovae. (2012): Identification and examination of some probiotic properties of Lactobacillus plantarum F3. Food Environ. Safety, 4, 22-29.

Doleyres, Y., Fliss, I. \& LACroix, C. (2004): Increased stress tolerance of Bifidobacterium longum, and Lactococcus lactis, produced during continuous mixed-strain immobilized-cell fermentation. J. Appl. Microbiol., 97(3), 527-539.

FAO/WHO (2002): Guidelines for the evaluation of probiotics in food. Food and Agriculture Organization of the United Nations and World Health Organization. Working Group Report, 11 pages.

Gouin, S. (2004): Microencapsulation: industrial appraisal of existing technologies and trends. Trends Food Sci. Tech., 15(7-8), 330-347.

Gross, C.R.F. \& FÁvaro-Trindade, C.S. (2004): Stability of free and immobilized Lactobacillus acidophilus and Bifidobacterium lactis in acidified milk and of immobilized B. lactis in yoghurt. Braz. J. Microbiol., 35(1-2), 151-156.

He, C., Man, H., Shu, G., QI, M. \& TAO, Q. (2011): Effect of prebiotics on growth of Bifidobacterium bifidum. International Conference on Human Health and Biomedical Engineering, Jilin, China, 2011 Aug 19-22, Proceeedings, pp. 981-984.

Martoni, C., Bhathena, J., Jones, M.L., Urbanska, A.M., Chen, H. \& Prakash, S. (2007): Investigation of microencapsulated BSH active Lactobacillus in the simulated human GI tract. J. Biomed. Biotechnol., 2007(7), 13684.

Matias, N.S., Padilha, M., Bedani, R. \& SaAd, S.M. (2016): In vitro gastrointestinal resistance of Lactobacillus acidophilus la-5 and Bifidobacterium animalis BB-12 in soy and/or milk-based synbiotic apple ice creams. Int. J. Food Microbiol., 234, 83-93.

Sнан, N.P. (2007): Functional cultures and health benefits. Int. Dairy J., 17(11), 1262-1277.

Sheu, T.Y., Marshall, R.T. \& Heymann, H. (1993): Improving survival of culture bacteria in frozen desserts by microentrapment. J. Dairy Sci., 76(7), 1902-1907.

Shi, L.E., Li, Z.H., Li, D.T., Xu, M., Chen, H.Y., Zhang, Z.L. \& TANG, Z.X. (2013a): Encapsulation of probiotics Lactobacillus bulgaricus in alginate-milk microspheres and evaluation of survival in simulated gastrointestinal conditions. J. Food Eng., 117, 99-104.

Shi, L.E., Zhang, Z.L., Song, Y.Q., Zhou, M.L., Yu, W.M. \& TANG, Z.X. (2013b): Encapsulation of Lactobacillus bulgaricus in carragenan-locust bean gum coated milk microspheres with double layer structure. LWT - Food Sci. Tech., 54, 147-151.

Shu, G.W., Hu, M., Qin, T., Chen, H. \& MA, Q. (2012): Effect of fructo-oligosaccharide, isomalto-oligosaccharide, inulin and xylo-oligosaccharide on survival of B. bifidum during freeze-drying. Adv. Mater. Res., 382, 454457.

Sohail, A., Turner, M.S., Coombes, A., Bostrom, T. \& Bhandari, B. (2011): Survivability of probiotics encapsulated in alginate gel microbeads using a novel impinging aerosols method. Int. J. Food Microbiol., 145(1), 162-168.

SouZA, C.H.B. \& SAAD, S.M.I. (2009): Viability of Lactobacillus acidophilus LA-5 added solely or in co-culture with a yoghurt starter culture and implications on physico-chemical and related properties of minas fresh cheese during storage. LWT - Food Sci. Tech., 42(2), 633-640.

Sun, W. \& GRIFfiths, M.W. (2000): Survival of Bifidobacteria in yogurt and simulated gastric juice following immobilization in gellan-xanthan beads. Int. J. Food Microbiol., 61(1), 17-25. 